\title{
A Grande Vitória
}

\section{Colega,}

É com orgulho e alegria que a Diretoria da FEBRASGO comunica aos seus associados, que a Revista Brasileira de Ginecologia e Obstetrícia, a nossa RBGO, preencheu os critérios para ser incluída na base de dados SciELO.

O acesso à informação técnica-científica atualizada é essencial para o desenvolvimento econômico e social, especialmente para apoiar os processos de tomada de decisão no planejamento, formulação e aplicação de politicas públicas como também para apoiar o desenvolvimento profissional. O resultado da pesquisa científica é validado principalmente por sua publicação em revistas científicas. Nos países em desenvolvimento os periódicos científicos enfrentam graves barreiras de distribuição, o que limita o acesso e o uso da informação gerada localmente.

Os Critérios SciELO Brasil estão definidos no Projeto SciELO, coordenado pela FAPESP e pela BIREME, cujo objetivo principal é contribuir para o desenvolvimento da pesquisa científica nacional, para o aperfeiçoamento e ampliação dos meios de divulgação, publicação e avaliação dos seus resultados.

Ainda, o Modelo SciELO, contém métodos para medir o uso e o impacto dos periódicos científicos.

Para a sua inclusão na base de dados SciELO não foram necessárias mudanças substanciais na linha editorial da revista, pois, muitas das normas internacionais já eram por nós adotadas.

Tal fato representa uma vitória de todos. Primeiro da RBGO, que passa a ser a única publicação em Ginecologia e Obstetrícia do SciELO em toda América Latina. Dos editores e revisores que, há anos, vêm inovando, aprimorando e qualificando este que se constitui no mais importante veículo de divulgação de pesquisas originais realizadas em Ginecologia e Obstetrícia em nosso país. Da FEBRASGO que oferece aos seus associados um periódico da mais alta qualificação. Dos colegas que pesquisam e enviam seus trabalhos para publicação na RBGO, pois deles depende o que nela vai impresso. Dos Tocoginecologistas, que recebem uma revista à altura do que merecem e do que a FEBRASGO luta para lhes oferecer.

\section{A Diretoria}

